\title{
The use of insulin declines as patients live farther from their source of care: results of a survey of adults with type 2 diabetes Benjamin Littenberg*1,2, Kaitlin Strauss ${ }^{1}$, Charles D MacLean ${ }^{1}$ and Austin R Troy ${ }^{3}$
}

\author{
Address: ${ }^{1}$ Division of General Internal Medicine, University of Vermont, Burlington, Vermont, USA, ${ }^{2}$ College of Nursing and Health Sciences, \\ University of Vermont, Burlington, Vermont, USA and ${ }^{3}$ Rubenstein School of Natural Resources, University of Vermont, Burlington, Vermont, USA \\ Email: Benjamin Littenberg* - benjamin.littenberg@vtmednet.org; Kaitlin Strauss - kaitlin.strauss@uvm.edu; \\ Charles D MacLean - charles.maclean@vtmednet.org; Austin R Troy - Austin.troy@uvm.edu \\ * Corresponding author
}

Published: 27 July 2006

BMC Public Health 2006, 6:198 doi:10.1 186/147/-2458-6-198

This article is available from: http://www.biomedcentral.com/I47I-2458/6/198

(c) 2006 Littenberg et al; licensee BioMed Central Ltd.

This is an Open Access article distributed under the terms of the Creative Commons Attribution License (http://creativecommons.org/licenses/by/2.0), which permits unrestricted use, distribution, and reproduction in any medium, provided the original work is properly cited.
Received: 14 April 2006

Accepted: 27 July 2006

\begin{abstract}
Background: Although most diabetic patients do not achieve good physiologic control, patients who live closer to their source of primary care tend to have better glycemic control than those who live farther away. We sought to assess the role of travel burden as a barrier to the use of insulin in adults with diabetes

Methods: 78I adults receiving primary care for type 2 diabetes were recruited from the Vermont Diabetes Information System. They completed postal surveys and were interviewed at home. Travel burden was estimated as the shortest possible driving distance from the patient's home to the site of primary care. Medication use, age, sex, race, marital status, education, health insurance, duration of diabetes, and frequency of care were self-reported. Body mass index was measured by a trained field interviewer. Glycemic control was measured by the glycosolated hemoglobin AIC assay.

Results: Driving distance was significantly associated with insulin use, controlling for the covariates and potential confounders. The odds ratio for using insulin associated with each kilometer of driving distance was 0.97 (95\% confidence interval $0.95,0.99 ; P=0.01)$. The odds ratio for using insulin for those living within $10 \mathrm{~km}$ (compared to those with greater driving distances) was 2.29 $(1.35,3.88 ; P=0.02)$.

Discussion: Adults with type 2 diabetes who live farther from their source of primary care are significantly less likely to use insulin. This association is not due to confounding by age, sex, race, education, income, health insurance, body mass index, duration of diabetes, use of oral agents, glycemic control, or frequency of care, and may be responsible for the poorer physiologic control noted among patients with greater travel burdens.
\end{abstract}

\section{Background}

In spite of the widespread availability of efficacious therapies, adequate management of diabetes remains an elu- sive goal $[1,2]$. Barriers to optimum control of diabetes in community settings include poor practice management and organization [3-5], poor adherence to medical advice 
by patients [6], comorbid illnesses [7], and lack of health insurance [8]. Although appropriate use of insulin can lead to better glycemic control, as well as a better selfreported quality of life [9], many patients and providers underutilize insulin for a variety of reasons, including clinical inertia [10] and medical concerns [11].

Geography has long been recognized as a determinant of health status. For example, cerebrovascular disease clusters in the "stroke belt" of the southeastern United States [12]. Death rates among European elders vary two-fold depending on place [13]. Americans are more likely to be disabled in certain parts of the country than others [14,15].

Recently, use of Geographic Information Systems has led to insight about spatial prevalence and treatment of many conditions including diabetes [16,17]. Geographic patterns of health care utilization have also revealed important variations in treatment patterns of various conditions among even small geographic areas $[18,19]$. Mammography [20], knee joint replacement [21], treatment of colorectal cancer [22], and lower extremity amputation [23], to name a few examples, have all been shown to vary importantly by geographic location of the population independent of clinical status at the individual level.

To some degree, these variations may be due to variation among the providers (both individual and institutional) whose various practice styles can introduce patterns of care that vary at the geographic level [24]. However, in some cases there is evidence that local geography can, itself, serve as a barrier to care. Travel burden, measured as driving distance or access to transportation, has been linked to health care utilization [25-27]. In diabetes care specifically, increased travel burden, as measured by driving distance, has been associated with poorer glycemic control [28].

Modern Geographic Information Systems (GIS) make it relatively inexpensive to determine the most direct driving route between two known addresses. For rural areas, where routes are often circuitous, driving distance has been shown to be a more accurate marker of travel burden than straight-line measures [29].

In this study, we examined the relationship between insulin usage and the driving distance from a patient's home to their site of primary care. We sought to evaluate the hypothesis that insulin use is associated with driving distance and to evaluate whether any observed relationship was due to confounding by social, economic or clinical factors.

\section{Methods}

This study was part of a larger project, the Vermont Diabetes Information System (VDIS), a cluster-randomized trial of a laboratory-based diabetes decision support system in a region-wide sample of 7406 adults with diabetes from 73 primary care practices [30]. VDIS delivers improved laboratory information services to patients and providers to support and enhance their decision making about diabetes treatment and monitoring. The data presented here were collected at baseline before the VDIS intervention began. A field survey targeted at a sub-sample of subjects was designed to provide a better understanding of the non-laboratory features of the patients. Subjects were selected at random from the patients participating in the VDIS trial and invited by phone to participate in an inhome interview. Patient names were randomly sorted and patients contacted by telephone until a sample of approximately $15 \%$ of the patients from each practice agreed to an interview. If a subject could not be contacted, another name was chosen from the list. Therefore, many subjects were called only once or twice before being excluded from the study. We attempted to contact 4,209 patients and reached $1,576(37 \%)$. Of these, $1,006(64 \%)$ agreed to be interviewed.

Subjects who agreed were mailed a questionnaire and were scheduled for an interview by a trained field interviewer. The questionnaire covered multiple domains including demographics and medication usage. During the visit, the interviewer reviewed any missing or ambiguous questionnaire items. If necessary, the interviewer read the questions aloud for subjects and recorded their responses for them. Then the interviewer measured the subject's height, weight and blood pressure. The subjects were asked to produce every medicine they had used in the past month for the interviewer to record. The interviews took place during the baseline phase of the study before any interventions were in place. The protocol was approved by the institutional review board of the University of Vermont.

Income was recorded in seven ordered self-reported categories from less than $\$ 15,000$ per year to $\$ 100,000$ per year or more. For analysis, we collapsed these into two categories: above and below $\$ 30,000$ per year. We collapsed self-reported education into High School Graduate or not. We collapsed self-reported race and ethnicity into two categories: Non-Hispanic white and all others. Marital status was collapsed into two categories: married (including living as married) and all others (single, widowed, divorced or separated). We recorded the presence or absence of five categories of health insurance: private (commercial indemnity or health maintenance organizations), Medicare, Medicaid, military (including active duty or Veterans benefits) and uninsured. Subjects were asked to recall the 
number of visits they made to their primary care provider (PCP) in the last month and whether they had seen an endocrinologist in the last year. Glycemic control was estimated by the latest glycosolated hemoglobin A1C assay performed at the local clinical laboratory.

We included all interviewed subjects who provided complete data for all variables. Subjects were excluded from analysis as potentially having type 1 diabetes if they used insulin without any oral hypoglycemic agents and were diagnosed with diabetes before age 30 . We compared the characteristics of the included subjects to all interviewed but excluded subjects using t-tests, $\chi^{2}$ tests and Fisher exact tests.

The shortest driving distance from the patients' homes to their site of care was calculated in kilometers using ArcView 3.3 by Environmental Systems Research Institute, Inc., and a geographic data set of roads purchased from TeleAtlas, Inc. Locations were geocoded by matching addresses to the street layer, which is coded with address ranges. Driving distance was defined as the shortest distance along roads and highways. We also categorized subjects dichotomously as living less than or greater than 10 $\mathrm{km}$ from their PCP $(10 \mathrm{~km}=6.2$ miles $)$.

We compared the driving distances of insulin users and non-users with the Wilcoxon rank-sum test and the $\chi^{2}$ test. We divided observations by their driving distance into four quartiles and compared the insulin use for each quartile. We tested the significance of the trend in insulin use across quartiles with a nonparametric extension of the Wilcoxon rank-sum test [31]. Because nonparametric procedures are not available, we used analysis of variance (ANOVA) to test for clustering of factors within providers' practices and expressed this phenomenon as the intraprovider (or intra-cluster) correlation coefficient (ICC) [32]. We used logistic regression to test the association between insulin use (present or absent) and each marker of travel burden (distance in kilometers and the dichotomous variable) by calculating odds ratios (OR) and their 95\% confidence intervals (CI). We repeated the analysis controlling for age, sex, race, education, income, health insurance, body mass index, use of any oral hypoglycemic agents, glycemic control, and duration of diabetes in years. We adjusted the standard errors and significance values of the multivariate analyses for clustering within provider practices [33]. We used Stata 8.2 for all analyses.

\section{Results}

\section{Description of population}

The analysis included 781 patients from 68 practices who completed the interview without missing values for any of the covariates, had an address that could be geographically referenced, and did not meet criteria for type 1 dia- betes. They were predominantly elderly ( $51 \%$ age 65 or more), female (54\%), white (97\%), and married (63\%). Seventy-six percent had graduated high school and 57\% earned less than $\$ 30,000$ per year. Most had some form of health insurance. 136 subjects (17\%) used insulin and 666 did not. Excluded subjects had a longer duration of diabetes, less use of insulin, greater use of oral hypoglycemic agents and Medicare health insurance, lower BMI, and somewhat lower incomes. See Table 1.

Vermont and the neighboring regions where the subjects lived are largely rural or exurban (a pattern of fragmented, low-density residential development relatively far from traditional urban centers, but not associated with agricultural or other extractive land uses [34]). Vermont has 240 physicians including 86 Primary Care Physicians per 100,000 population. These are higher than the US national averages of 198 physicians and 69 primary care physicians per 100,000 population [35]. The median driving distance was $5.3 \mathrm{~km}$ (4.8 miles) with over $90 \%$ of the respondents living within $30 \mathrm{~km}$ (18.8 miles) of their PCP.

\section{Bivariate association of driving distance and insulin use} Insulin users had shorter driving distances than non-users when considering the mean $(13.0 \mathrm{~km} v s .9 .2 \mathrm{~km})$ or virtually any percentile of the driving distance distributions $(P$ $=0.005$; see Table 2). Figure 1 shows the distribution of driving distances for users and non-users of insulin. Those living greater than $10 \mathrm{~km}$ away were less likely to use insulin than those living nearer $(11.9 \%$ vs. $20.1 \%, P=0.002)$. This relationship was also demonstrated by unadjusted logistic regression. The odds ratio for insulin use associated with each kilometer of driving distance was 0.98 (CI $0.96,0.99 ; P=0.01)$. The $\mathrm{OR}$ for living within $10 \mathrm{~km}$ was 1.88 (CI $1.25,2.82 ; P=0.003$ ). The proportion of subjects using insulin decreased monotonically from the nearest quartile of subjects $(22 \%)$ to the quartile with the greatest driving distance $(10 \%, P=0.004)$. See Figure 2 .

\section{Bivariate consideration of potential confounders}

Insulin users were more often male $(48 \%$ vs. $37 \%, P=$ $0.03)$, had higher body mass indices $\left(36 v s .34 \mathrm{~kg} / \mathrm{m}^{2}, P=\right.$ $0.001)$ and had been diabetic longer ( 16 vs. 8 years, $P<$ $0.001)$. They were seen in primary care more often $(2.1 \mathrm{vs}$. 1.5 visits per month, $P<0.001)$ were more likely to see specialty providers $(37 \% v$ s. $11 \%$ seen in last year, $P<$ $0.001)$, less likely to use oral hypoglycemic agents $(57 \%$ vs. $72 \%, P<0.001)$ and were more likely to earn less than $\$ 30,000$ per year $(66 \% v$ s. $56 \%, P=0.03)$. Other differences between users and non-users did not achieve statistical significance. See Table 3.

Although insulin users lived closer to their providers and had more visits than non-users, there was no significant 
Table I: Population characteristics of $78 \mathrm{I}$ included and 225 excluded subjects

\begin{tabular}{|c|c|c|c|}
\hline Characteristic & Included & Excluded & $P$ \\
\hline Age (years) & $64.68(22-93)$ & $65.6(30-89)$ & 0.16 \\
\hline Senior citizen & $51.3 \%$ & $57.5 \%$ & 0.11 \\
\hline Male & $46.1 \%$ & $44.6 \%$ & 0.70 \\
\hline Race - White, non-Hispanic & $97.1 \%$ & $98.1 \%$ & 0.41 \\
\hline Married or living as married & $62.7 \%$ & $60.9 \%$ & 0.64 \\
\hline Education - High School Graduate & $76.3 \%$ & $72.3 \%$ & 0.24 \\
\hline Income less than $\$ 30,000$ per year & $57.7 \%$ & $66.0 \%$ & 0.07 \\
\hline \multicolumn{4}{|l|}{ Health Insurance } \\
\hline Private & $58.3 \%$ & $59.1 \%$ & 0.82 \\
\hline Medicare & $58.1 \%$ & $66.7 \%$ & 0.03 \\
\hline Medicaid & $20.9 \%$ & $22.8 \%$ & 0.56 \\
\hline Military or Veterans' & $5.0 \%$ & $6.5 \%$ & 0.41 \\
\hline None & $2.3 \%$ & $2.8 \%$ & 0.65 \\
\hline Body Mass Index $\left(\mathrm{kg} / \mathrm{m}^{2}\right)$ & $34.1(16-65)$ & $32.7(18-68)$ & 0.01 \\
\hline Duration of diabetes (years) & $9.4(0.02-61)$ & $14.3(0.03-62)$ & $<0.001$ \\
\hline Glycosolated hemoglobin AIC (\%) & $7.1(4.7-13.5)$ & $7.1(4.0-12.9)$ & 0.67 \\
\hline Glycosolated hemoglobin AIC less than $7 \%$ & $57.9 \%$ & $58.9 \%$ & 0.44 \\
\hline Primary care visits in the last month (visits) & $1.6(0-25)$ & $1.7(0-16)$ & 0.85 \\
\hline Endocrinology visit in the last year & $14.9 \%$ & $20.0 \%$ & 0.08 \\
\hline Insulin use & $16.8 \%$ & $25.0 \%$ & 0.01 \\
\hline Oral agent use & $69.4 \%$ & $57.1 \%$ & 0.001 \\
\hline \multicolumn{4}{|l|}{ Travel burden } \\
\hline Driving distance $(\mathrm{km})$ & $12.4(0.1-340)$ & $12.2(0.1-59)$ & 0.78 \\
\hline Driving distance less than $10 \mathrm{~km}$ & $59.0 \%$ & $56.3 \%$ & 0.51 \\
\hline
\end{tabular}

Some respondents reported more than one type of health insurance. The sample sizes for excluded subjects vary as some characteristics had missing values. There are no missing values for the included subjects. $P$ values calculated by Wilcoxon rank-sum or $\chi^{2}$ tests as appropriate.

relationship between PCP visits and driving distance. Expressed as a continuous variable in $\mathrm{km}$, the rank-sum correlation of distance with the number of PCP visits in the last month was $-0.03(P=0.46)$. Likewise, the number of visits was similar in those living within $10 \mathrm{~km}$ and their more distant counterparts (1.6 vs. 1.5 visits per month, $P$ $=0.63)$.

Similarly, there was little difference in travel burden to primary care for those seeing an endocrinologist compared to those who did not (12.1 vs. $12.4 \mathrm{~km}, P=0.72)$. The use of an endocrinologist was similar among those who lived within $10 \mathrm{~km}$ of their PCP and those who did not $(15 \%$ vs. $17 \%, P=0.39)$.

Table 2: Driving distances of insulin users and non-users

\begin{tabular}{lcc}
\hline Percentile & $\begin{array}{c}\text { Insulin } \\
\text { Users }(n=136)\end{array}$ & $\begin{array}{c}\text { Non-Users } \\
(n=666)\end{array}$ \\
\hline $0^{\text {th }}$ (Minimum) & 0.4 & 0.1 \\
$10^{\text {th }}$ & 0.6 & 1.4 \\
$25^{\text {th }}$ & 2.3 & 2.7 \\
$50^{\text {th }}$ (Median) & 5.3 & 8.3 \\
$7^{\text {th }}$ & 11.7 & 17.0 \\
$90^{\text {th }}$ & 20.0 & 29.5 \\
$10^{\text {th }}$ (Maximum) & 51.9 & 340.4 \\
\hline
\end{tabular}

All distances are in kilometers.
To explore the possibility that confounding by provider style is responsible for the apparent association between travel distance and insulin, we calculated the intra-provider correlation coefficients for both travel distance and insulin use. Insulin use was not significantly variable among providers (ICC $=0.004, P=0.41$ ). However, there was significant clustering of travel distance by provider (ICC $=0.18, P<0.001)$. In other words, some providers tended to have patients who live far away while others tended to have more local practices.

\section{Multivariate model to control for potential confounders}

After adjusting for age, sex, race, marital status, education, income, health insurance, body mass index, duration of diabetes, glycemic control, use of oral hypoglycemic agents, number of visits to the PCP and consultation with an endocrinologist, the OR for using insulin associated with each kilometer of driving distance was 0.97 (CI 0.95, $0.99 ; P=0.013$ ). See Table 4 . The OR for using insulin for those living within $10 \mathrm{~km}$ was 2.29 (CI 1.35, 3.88; $P=$ 0.002). See Table 5 .

\section{Discussion}

The greater the driving distance for adults with diabetes to their source of primary care, the less likely they are to be using insulin. This relationship is not due to confounding 


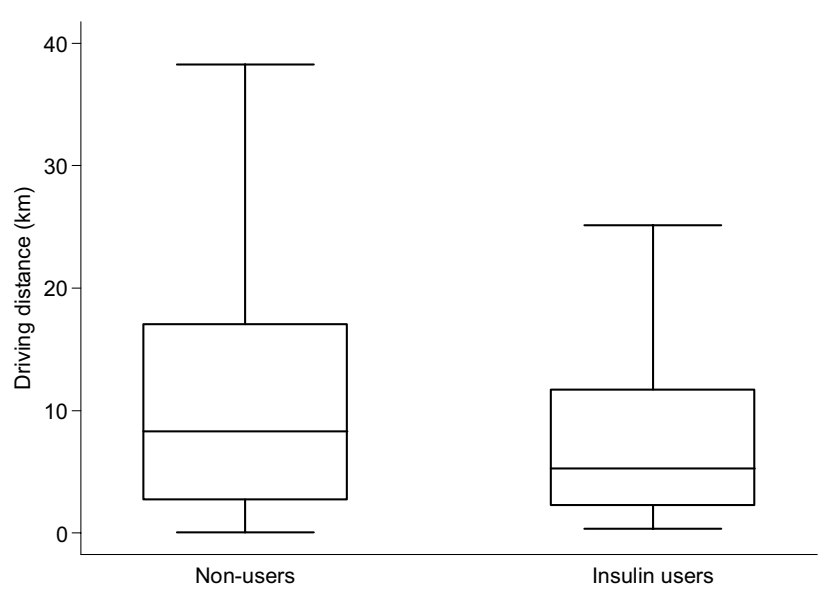

Figure I

Distribution of driving distances for insulin users and non-users. The middle line of each box represents the median driving distance. The boxes span the inter-quartile range of driving distances from the $25^{\text {th }}$ to the $75^{\text {th }}$ percentiles. The whiskers span the outer quartiles. Outlier or outside values are excluded so that the medians and quartiles can better be compared.

by the social, demographic, or clinical factors measured here.

The mechanism for this relationship is unclear. Perhaps patients and physicians are concerned about the risks of insulin and are reluctant to use it if they feel the patient lives too far away from care for rescue in the event of hypoglycemia. We have no direct data on the attitudes of these decision makers in this regard.

Perhaps patients with more visits can be stepped through the various regimens more promptly and started on insulin sooner. In other words, travel burden might influence therapy through the frequency of medical contact. However, we found little relationship between distance and visit frequency. Furthermore, adjusting for frequency of visits (either to primary or specialty care) had little effect upon the relationship between distance and insulin use.

Possibly, providers who systematically avoid insulin in all their patients systematically attract patients from farther afield. This is unlikely given the low clustering of insulin use within providers and the minimal impact of correcting for clustering in the multivariate analyses. Although providers do systematically vary in the size of their catchment areas, they do not appear to have systematic tendencies to use or avoid insulin.

Previous findings suggest that patients who travel farther to primary care have poorer physiologic control [28].

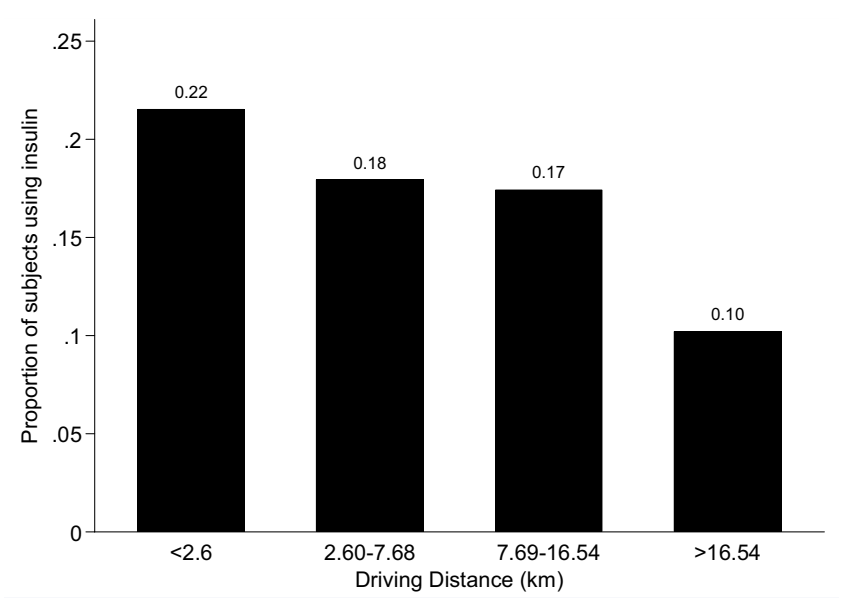

Figure 2

Insulin use over the range of driving distances. Driving distances were divided into quartiles of 195 or 196 subjects each. The heights of the bars represent the proportion of subjects in each quartile who use insulin.

Likewise, rural patients, who generally have higher travel burdens, tend to have poorer health status [36]. It is not known if these effects are completely explained by lower intensity of therapy. Nonetheless, it speaks to the need to reassess care for rural and exurban patients. Several possible approaches come to mind. Medical services, especially primary care, could be dispersed more widely. Although the economic and cultural barriers to placing physicians in underserved areas are formidable [37], greater use of home or worksite visits by traveling or circuit providers (physicians, nurses, physician assistants, etc.) could be attractive. Also, new technologies could replace or complement traditional face-to-face personal care. The telephone, facsimile, and the Internet have potential to alleviate the barriers associated with distance in health (as they have for business, education, government and other endeavors) [38]. However, current insurance reimbursement schemes generally discourage services that are not provided in person.

\section{Limitations}

Because the study population was drawn from primary care practices in mostly rural and exurban regions of Vermont, New Hampshire, and New York, the population was mostly white and insured. The results may not generalize to urban patients or populations with poor financial access to care. Conversely, patients in lower density areas of America (such as the Great Plains or rural Alaska) may have significantly longer driving distances to access primary care.

Although we controlled for a number of potentially confounding variables, residual confounding by unmeasured 
Table 3: Social, geographic, and clinical correlates of insulin use (univariate comparisons)

\begin{tabular}{|c|c|c|c|}
\hline \multirow[t]{2}{*}{ Characteristic } & \multicolumn{2}{|c|}{ Proportion or mean and range } & \multirow[t]{2}{*}{$P$} \\
\hline & $\begin{array}{l}\text { Insulin Users } \\
(n=13 I)\end{array}$ & $\begin{array}{l}\text { Non-Users } \\
(n=650)\end{array}$ & \\
\hline \multicolumn{4}{|l|}{ Travel burden } \\
\hline Driving distance $(\mathrm{km})$ & $9.38(0.4-52)$ & $13.0(0.1-340)$ & 0.005 \\
\hline Driving distance less than $10 \mathrm{~km}$ & $71.0 \%$ & $56.6 \%$ & 0.002 \\
\hline Age (years) & $65.5(36-88)$ & $64.4(22-93)$ & 0.36 \\
\hline Male & $37.40 \%$ & $47.9 \%$ & 0.03 \\
\hline Race - White, non-Hispanic & $96.2 \%$ & $97.2 \%$ & 0.52 \\
\hline Married or living as married & $60.3 \%$ & $63.2 \%$ & 0.53 \\
\hline High School Graduate & $77.9 \%$ & $76.0 \%$ & 0.65 \\
\hline Income less than $\$ 30,000$ per year & $65.7 \%$ & $56.2 \%$ & 0.045 \\
\hline \multicolumn{4}{|l|}{ Health Insurance } \\
\hline Private & $59.6 \%$ & $58.0 \%$ & 0.74 \\
\hline Medicare & $63.4 \%$ & $57.1 \%$ & 0.18 \\
\hline Medicaid & $22.9 \%$ & $20.5 \%$ & 0.53 \\
\hline Military or Veterans' & $6.9 \%$ & $4.6 \%$ & 0.28 \\
\hline None & $1.5 \%$ & $2.5 \%$ & 0.52 \\
\hline Body Mass Index $\left(\mathrm{kg} / \mathrm{m}^{2}\right)$ & $35.9(18-53)$ & $33.8(16-65)$ & 0.001 \\
\hline Duration of diabetes (years) & $16.0(0.1-44)$ & $8.1(0.02-61)$ & $<0.001$ \\
\hline Glycosolated hemoglobin AIC (\%) & $7.8(5.4-13.3)$ & $7.0(4.7-13.5)$ & $<0.001$ \\
\hline Glycosolated hemoglobin AIC $<7 \%$ & $36.6 \%$ & $62.2 \%$ & $<0.001$ \\
\hline Oral hypoglycemic agent use & $57.2 \%$ & $71.9 \%$ & 0.001 \\
\hline Endocrinology visit in the last year & $36.6 \%$ & $10.5 \%$ & $<0.001$ \\
\hline Primary care visits in the last month & $2.1(0-20)$ & $1.5(0-25)$ & $<0.001$ \\
\hline
\end{tabular}

variables could account for some or all of the observed relationship between driving distance and insulin use.

We measured travel burden as the driving distance from home to the PCP. However, some patients may travel to their PCP from work or another location, receive home visits, have more or less difficult travel routes, or face very different travel burdens due to handicap or access to transportation services. Similarly, geocoding (the process of assigning a geographic location to an address) is subject to random error, which may be larger in rural than urban areas [39]. Unless these factors are associated with both distance from home as we measured it and insulin use, they are unlikely to bias our estimates. Indeed, they would be expected to contribute random error and reduce the statistical significance of the analyses.

Although we recruited the subjects from primary care practices, some subjects may have been receiving their diabetes care from a specialist and would therefore be more likely to be using insulin. Although these patients presumably travel farther on average to the specialist, it is unlikely that they systematically travel a shorter distance to primary care.

Although we eliminated subjects who apparently have type 1 diabetes, there are no perfectly reliable criteria for distinguishing type 1 from type 2 diabetes in this setting. Repeating the analyses with the 23 type 1 subjects included had little effect on the results, suggesting that the possible inclusion of some type 1 patients would not be consequential.

The models do not include all variables that may have a role in explaining the use of insulin. Such an exercise is beyond the scope of this report. Rather, we sought only to test the hypothesis that insulin use and driving distance are independently related. Therefore, we included only those variables that could confound the apparent relationship between insulin use and driving distance.

\section{Conclusion}

Adults with type 2 diabetes who live farther from their source of primary care are less likely to use insulin. This association is not due to confounding by age, sex, race, education, income, health insurance, body mass index, duration of diabetes, use of oral hypoglycemic agents, or frequency of primary or specialty care and may be responsible for the poorer physiologic control noted in rural patients.

\section{Competing interests}

The author(s) declare that they have no competing interests. 
Table 4: Social, geographic, and clinical correlates of insulin use (multivariate model with a continuous distance measure)

\begin{tabular}{lccc}
\hline Characteristic & Odds Ratio & $95 \% \mathrm{Cl}$ & $P$ \\
\hline Driving distance (km) & 0.97 & $0.95,0.99$ & 0.013 \\
Age (years) & 1.02 & $0.99,1.05$ & 0.16 \\
Male & 0.69 & $0.43,1.10$ & 0.12 \\
Race - White, non-Hispanic & 0.97 & $0.31,3.02$ & 0.95 \\
Married or living as married & 1.44 & $0.85,2.45$ & 0.18 \\
High School Graduate & 1.23 & $0.65,2.33$ & 0.52 \\
Low income & 1.32 & $0.72,2.45$ & 0.37 \\
Health Insurance & & & \\
$\quad$ Private & 1.42 & $0.73,2.75$ & 0.30 \\
$\quad$ Medicare & 0.98 & $0.52,1.84$ & 0.95 \\
$\quad$ Medicaid & 1.19 & $0.62,2.30$ & 0.61 \\
$\quad$ Military or Veterans' & 1.13 & $0.46,2.78$ & 0.79 \\
$\quad$ None & 0.73 & $0.14,3.87$ & 0.71 \\
Body Mass Index (kg/m ${ }^{2}$ ) & 1.06 & $1.02,1.09$ & 0.003 \\
Duration of diabetes (years) & 1.08 & $1.05,1.10$ & $<0.001$ \\
Glycosolated hemoglobin AIC (\%) & 1.54 & $1.32,1.81$ & $<0.001$ \\
Oral hypoglycemic agent use & 0.36 & $0.22,0.57$ & $<0.001$ \\
Endocrinology visit in the last year & 4.78 & $2.75,8.31$ & $<0.001$ \\
Primary care visits in the last month & 1.06 & $0.99,1.14$ & 0.11 \\
\end{tabular}

\section{Authors' contributions}

BL conceived the question, obtained funding, performed the final analysis, and drafted the manuscript. KS performed parts of the analysis and reviewed the manuscript. CDM participated in the design of the study, managed the data collection, and reviewed the manuscript. ART participated in the design of the study, advised on analysis, assisted with the Geographic Information System, and reviewed the manuscript.

\section{Acknowledgements}

This work was funded by the US National Institute of Diabetes and Digestive and Kidney Diseases (ROI DK6 I I 67 and K24 DK68380). The sponsor had no role in study design; in the collection, analysis, or interpretation of data; in the writing of the manuscript; or in the decision to submit the manuscript for publication.

\section{References}

I. Saaddine JB, Engelgau MM, Beckles GL, Gregg EW, Thompson T], Narayan KM: A diabetes report card for the United States: quality of care in the 1990s. Ann Intern Med 2002, 136(8):565-74.

2. Saydah SH, Fradkin J, Cowie CC: Poor control of risk factors for vascular disease among adults with previously diagnosed diabetes. JAMA 2004, 291 (3):335-42.

3. Cabana MD, Rand CS, Powe NR, Wu AW, Wilson MH, Abboud PA, Rubin HR: Why don't Physicians follow Clinical Practice Guidelines? - A Framework for Improvement. JAMA 1999, 282(I5): | 458 - I 465.

4. Frame $P$ : Health maintenance in clinical practice: strategies and barriers. Am Fam Phys 1992, 45: I 192-1200.

5. Stolar MW: Clinical management of the NIDDM patient. Impact of the American Diabetes Association practice guidelines, 1985-1993. Endocrine Fellows Foundation Study Group. Diabetes Care 1995, I8(5):70I-7.

6. Warren LH, Hixenbaugh P: Adherence and diabetes. In Adherence to treatment in medical conditions Edited by: Myers LB, Midence K. Amsterdam: Harwood Academic; 1998.

7. Goel A, MacLean CD, Walrath D, Rubin A, Huston D, Jones MC, Niquette T, Kennedy AG, Beardall RW, Littenberg B: Adapting root
Table 5: Social, geographic, and clinical correlates of insulin use (multivariate model with a dichotomous distance measure)

\begin{tabular}{lccc}
\hline Characteristic & Odds Ratio & $95 \% \mathrm{Cl}$ & $P$ \\
\hline Driving distance less than $10 \mathrm{~km}$ & 2.29 & $1.35,3.88$ & 0.002 \\
Age (years) & 1.02 & $0.99,1.05$ & 0.13 \\
Male & 0.68 & $0.42,1.09$ & 0.11 \\
Race - White, non-Hispanic & 1.08 & $0.34,3.45$ & 0.90 \\
Married or living as married & 1.42 & $0.83,2.42$ & 0.20 \\
High School Graduate & 1.23 & $0.65,2.32$ & 0.53 \\
Low income & 1.30 & $0.70,2.40$ & 0.40 \\
Health Insurance & & & \\
$\quad$ Private & 1.41 & $0.72,2.74$ & 0.32 \\
$\quad$ Medicare & 0.99 & $0.53,1.85$ & 0.97 \\
$\quad$ Medicaid & 1.16 & $0.60,2.24$ & 0.66 \\
$\quad$ Military or Veterans' & 1.16 & $0.49,2.75$ & 0.74 \\
$\quad$ None & 0.73 & $0.14,3.85$ & 0.71 \\
Body Mass Index (kg/m ${ }^{2}$ ) & 1.06 & $1.02,1.10$ & 0.002 \\
Duration of diabetes (years) & 1.08 & $1.05,1.10$ & $<0.001$ \\
Glycosolated hemoglobin AIC (\%) & 1.56 & $1.32,1.83$ & $<0.001$ \\
Oral hypoglycemic agent use & 0.35 & $0.22,0.55$ & $<0.001$ \\
Endocrinology visit in the last year & 4.92 & $2.81,8.62$ & $<0.001$ \\
Primary care visits in the last month & 1.06 & $0.99,1.14$ & 0.09 \\
& & & \\
\hline
\end{tabular}

cause analysis to chronic medical conditions. It Comm J Qual Saf 2004, 30(4): 175-86.

8. Harris MI: Health care and health status and outcomes for patients with type 2 diabetes. Diabetes Care 2000, 23(6):754-8.

9. Bradley C, Speight J: Patient perceptions of diabetes and diabetes therapy: assessing quality of life. Diabetes Metab Res Rev 2002, 18(Suppl 3):S64-9.

10. Phillips LS, Branch WT, Cook CB, Doyle JP, El-Kebbi IM, Gallina DL, Miller CD, Ziemer DC, Barnes CS: Clinical inertia. Ann Intern Med 200I, I 35(9):825-34

II. Kuritzky L, Nelson SE: Assessing the controversies of insulin therapy in patients with type $\mathbf{2}$ diabetes mellitus. J Fam Pract 2005, 54(6):S3-6.

12. Wing S, Casper M, Davis WB, Pellom A, Riggan W, Tyroler HA Stroke mortality maps. United States whites aged 35-74 years, 1962-1982. Stroke 1988, 19(12):1507-13.

13. Amorim-Cruz JA, Haveman-Nies A, Schlettwein-Gsell D, De Henauw $\mathrm{S}$ : Gender, cohort and geographical differences in 10 -year mortality in elderly people living in 12 European towns. J Nutr Health Aging 2002, 6(4):269-74.

14. Porell FW, Miltiades HB: Regional differences in functional status among the aged. Soc Sci Med 2002, 54(8): I I8I-98.

15. Blumberg MS: Inter-area variations in age-adjusted health status. Med Care 1987, 25(4):340-53.

16. Dahlquist GG, Kallen BA: Time-space clustering of date at birth in childhood-onset diabetes. Diabetes Care 1996, 19(4):328-32.

17. Green C, Hoppa RD, Young TK, Blanchard JF: Geographic analysis of diabetes prevalence in an urban area. Soc Sci Med 2003, 57(3):55I-60.

18. Field KS, Briggs DJ: Socio-economic and locational determinants of accessibility and utilization of primary health-care. Health Soc Care Community 200I, 9(5):294-308.

19. Wennberg J, Gittelsohn: Small area variations in health care delivery. Science 1973, 182(I I7): I I02-8.

20. Glazier RH, Creatore MI, Gozdyra P, Matheson FI, Steele LS, Boyle E, Moineddin R: Geographic methods for understanding and responding to disparities in mammography use in Toronto, Canada. J Gen Intern Med 2004, I 9(9):952-61.

21. Yong PF, Milner PC, Payne JN, Lewis PA, Jennison C: Inequalities in access to knee joint replacements for people in need. Ann Rheum Dis 2004, 63(II): I 483-9.

22. Dejardin O, Herbert C, Velten M, Buemi A, Menegoz F, Maarouf N, Launoy G: Social and geographical factors influencing the delay in treatment for colorectal cancer. $\mathrm{Br}$ / Cancer 2004, 9I(9): $175 \mid-2$ 
23. Wrobel JS, Mayfield JA, Reiber GE: Geographic variation of lower-extremity major amputation in individuals with and without diabetes in the Medicare population. Diabetes Care 200I, 24(5):860-4.

24. Weinstein JN, Bronner KK, Morgan TS, Wennberg JE: Trends and geographic variations in major surgery for degenerative diseases of the hip, knee, and spine. Health Aff (Millwood) 2004. Web Exclusive:VAR8I-9

25. Arcury TA, Preisser JS, Gesler WM, Powers JM: Access to transportation and health care utilization in a rural region. $J$ Rural Health 2005, 2 I (I):3I-8.

26. Arcury TA, Gesler WM, Preisser JS, Sherman J, Spencer J, Perin J: The effects of geography and spatial behavior on health care utilization among the residents of a rural region. Health Serv Res 2005, 40(I): I35-55.

27. Borders TF, Rohrer JE, Hilsenrath PE, Ward MM: Why rural residents migrate for family physician care. J Rural Health 2000, I 6(4):337-48.

28. Strauss K, MacLean CD, Troy A, Littenberg B: Travel burden as a barrier to glycemic control in diabetes. J Gen Int Med 2006 in press.

29. Jordan H, Roderick P, Martin D, Barnett S: Distance, rurality and the need for care: access to health services in South West England. Int J Health Geogr 2004, 3( I):2I.

30. MacLean CD, Littenberg B, Gagnon MS, Reardon M, Turner PD, Jordan C: The Vermont Diabetes Information System (VDIS): Study Design and Subject Recruitment for a Cluster Randomized Trial of a Decision Support System in a Regional Sample of Primary Care Practices. Clinical Trials 2004, I:532-544.

31. Cuzick J: A Wilcoxon-type test for trend. Stat Med 1985, 4(I):87-90.

32. Kish L: Survey Sampling New York: John Wiley \& Sons; 1965.

33. Rogers WH: Regression standard errors in clustered samples. Stata Technical Bulletin 1993, 13:19-23.

34. Hansen A, Knight R, Marzluff J, Powell S, Brown K, Gude P, Jones A: Effects of exurban development on biodiversity Patterns, mechanisms, and research needs. Ecological Applications 2005, I 5(6): | 893-1905.

35. US Health Resources and Services Administration National Center for Health Workforce Analysis: Highlights from the 2000 State Health Workforce Profiles. 2004 [http://bhpr.hrsa.gov/health workforce/reports/statesummaries/vermont.htm].

36. Dixon J, Welch N: Researching the rural-metropolitan health differential using the 'social determinants of health'. Aust J Rural Health 2000, 8(5):254-60.

37. Hart LG, Salsberg E, Phillips DM, Lishner DM: Rural health care providers in the United States. J Rural Health 2002, I 8(Suppl):2 | |-32.

38. Wasson J, Gaudette C, Whaley F, Sauvigne A, Baribeau P, Welch HG: Telephone care as a substitute for routine clinic follow-up. JAMA 1992, 267(13): I 788-93.

39. Cayo MR, Talbot TO: Positional error in automated geocoding of residential addresses. Int J Health Geogr 2003, 2(I): I0.

\section{Pre-publication history}

The pre-publication history for this paper can be accessed here:

http://www.biomedcentral.com/1471-2458/6/198/pre pub
Publish with Biomed Central and every scientist can read your work free of charge

"BioMed Central will be the most significant development for disseminating the results of biomedical research in our lifetime. "

Sir Paul Nurse, Cancer Research UK

Your research papers will be:

- available free of charge to the entire biomedical community

- peer reviewed and published immediately upon acceptance

- cited in PubMed and archived on PubMed Central

- yours - you keep the copyright

Submit your manuscript here:

http://www.biomedcentral.com/info/publishing_adv.asp
BioMedcentral 